\title{
Engineering aspects of the selection of sites for the Third London Airport
}

J. L. DAWSON

\section{Mr D. A. Howells, $F$}

In $\S 25-35$ the Author discusses ideal airport layouts in relation to land take and taxiing distances. Has he considered the implications of an airport arrangement in which the aircraft does not move at all under its own power between landing and takeoff? Each routine operation could be carried out at a specific station along a flow line; the passenger disembarkation station and the one for embarkation would be widely separated. Fig. 16 gives an idea of what would be involved but the number of aircraft tow lines that could be accommodated need not be limited to two. Such a layout would need to be studied in some detail before a cost estimate could be made.

Professor J. R. D. Francis, Professor of Hydraulics, Department of Civil Engineering, Imperial College of Science and Technology

I should like to point out the Author's misuse in several places of the word 'hydrological'. The type of studies made for Foulness were entirely (from the Author's description) hydraulic in nature because no problem of the estimation and use of water resources was involved.

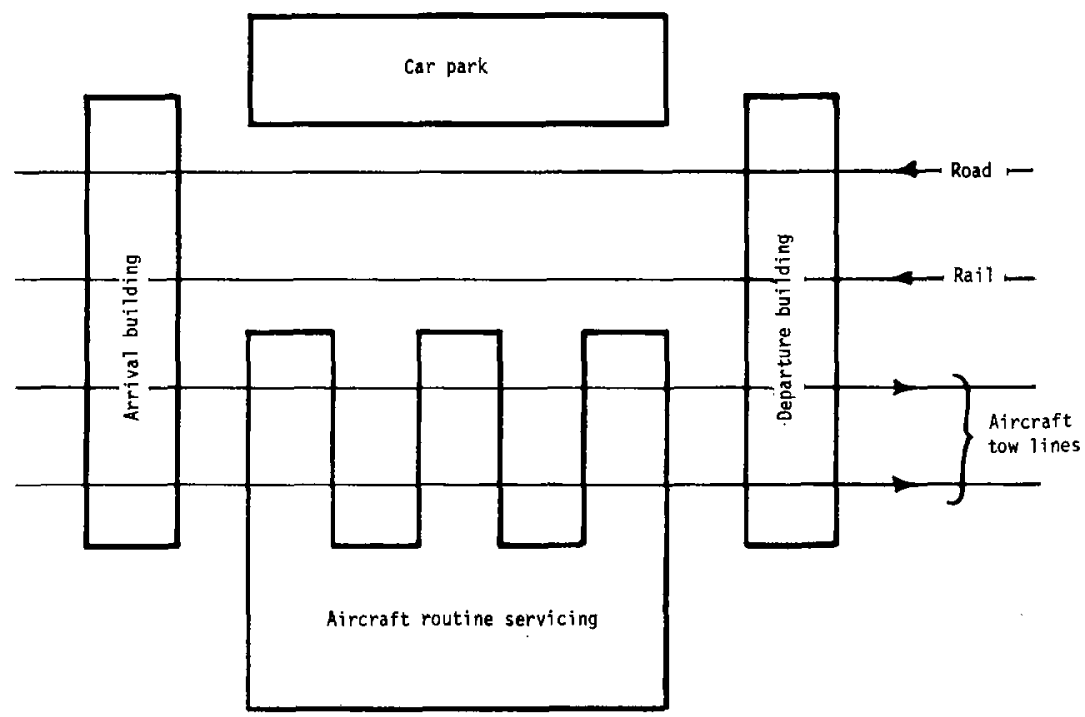

Fig. 16

Paper published: Proc. Instn Civ. Engrs, Part 2, 1972, 53, Sept., 337-367. 
Mr P. G. Clutterbuck, Project Manager, Dredging Investigations Ltd

I should like the Author to give additional information on his approach to the selection of reclamation filling heights considered for the Third London Airport site at Foulness.

123. In $\S 112$ it is stated that a low level polder scheme, larger than about 4250 ha, including extra land for industrial and other purposes, would be a strong contender for the airport.

124. The Paper infers that the same value was assumed in the assessment for high fill and low polder dyked reclamation. Is this correct? In my opinion the high level fill, being subject to a lower flooding risk, is more valuable. In support of this contention it is significant that the Dutch found, when developing the Maasvlakte Reclamation for the extension of the Port of Rotterdam, that the industrial users demanded and obtained reclamation site levels above expected flood level. It is acknowledged that the example of Schipol Airport, Amsterdam, is frequently quoted as being a successful airport constructed below sea level, but it must be appreciated that this is not a coastal location where a single dyke breach would cause immediate flooding.

\section{Mr E. W. Flaxman, Binnie \& Partners}

In $\S 42$ the Author discusses the disposal of sewage from the airport and lists the effluent standards assumed for discharges to various water courses together with the estimated costs of the cheapest arrangement at each site. It may appear anomalous that sewage disposal at Foulness should be more expensive than at any of the inland sites when the effluent standard to be attained would be less stringent. I should therefore like to explain how the effluent standards and cost estimates were derived.

126. Investigations into the disposal of sewage from the airport could not be divorced from the parallel investigations in respect of the accompanying urbanization. It was estimated that the sewage flow from the urbanization might ultimately amount to about 1200 litre/s and the sewage flow from the airport itself would be about 150 litre/s. At an early stage in the studies the authorities responsible for pollution control at the inland sites, particularly the Great Ouse River Authority, expressed serious concern at the effect which these additional quantities of sewage effluent might have on the quality of river water available for abstraction by water undertakings downstream of the sites. Nearly all sewage effluent arising from the inland sites would have to be discharged either above existing major intakes on the River Ouse and River Lee or above the proposed intake on the River Nene which was under consideration by Parliament at the time in connexion with the Empingham reservoir scheme.

127. It was eventually found that the impact on water abstractions could be kept within reasonable bounds by either avoiding or limiting the discharge of effluent to particular streams and by ensuring a high degree of treatment throughout. The most stringent effluent standard likely to be attainable with established methods of sewage treatment was taken to be $5: 5(\mathrm{mg} /$ litre of suspended solids and biochemical oxygen demand respectively). After informal discussions with the pollution officers concerned, standards of either 5:5 or 10:10 were adopted for all discharges from the inland sites, the figures selected in each case depending on the degree of dilution available in the river and the distance of the discharge point above major intakes.

128. At Foulness there appeared to be a possibility that sewage from the urbanization and the airport could be satisfactorily discharged into the sea. In preliminary discussions the Port of London Authority indicated that they would press for partial treatment of the sewage before discharge, irrespective of the position of the outfall, because of the possibility that sewage solids might affect the stability of side slopes in the dredged channels. This reduced the likelihood of a sea outfall scheme proving attractive. Further, reclamation of the Maplin sands in the future would affect the offshore regime and it would therefore not be possible to carry out during the 
study the essential hydrographic work required to establish whether or not a sea outfall would be feasible and economic.

129. Estimates of cost for sewage disposal at Foulness were therefore based on the discharge of treated effluent to the major estuaries. A 30:20 standard was adopted because of the presence of oyster layings in the estuary of the River Crouch and allowance was made for chlorination of the effluent before discharge.

130. The estimates summarized in Table 4 cover not only the cost of sewage treatment but also the cost of conveyance from the centre of the airport to the site of the treatment works. It is the relatively high cost of conveying the flow by pumping, combined with the difficult ground conditions anticipated, that results in the capital cost at Foulness being higher than at any of the other sites.

131. In each case the alternatives examined covered both joint and separate disposal of sewage from the airport and the urbanization. Only at Nuthampstead was it found economical to convey the flow from the airport for treatment with sewage from the urbanization; the relatively small operating costs shown in Table 4 reflect the savings obtained in this case from the operation of a much larger sewage treatment works. At all the other sites it was found that independent disposal of sewage from the airport would be less expensive than joint disposal; this was true whether the additional cost was allocated to the airport or if the total cost was apportioned between the airport and the urbanization in relation to flows.

\section{Mr F. A. Sharman, Sir William Halcrow \& Partners}

Mr Dawson has confined himself strictly to those engineering aspects of his subject which were dealt with by the official contributions to the work of the Roskill Commission mentioned in the Paper, and it is therefore left to those contributing to the discussion to submit that substantial volumes of engineering, as well as economic aviation and other professional studies, were made by others and may, like those described in the Paper, be of assistance in future work.

133. One of the most difficult tasks of the technical advisers in this problem, and one which is not specifically mentioned in the Paper, was to decide the borderline between engineering and policy, and also between engineering and the other related disciplines such as economics, sociology and planning. The engineers who were brought in to advise the principal group of local authorities concerned with the Third London Airport took the line that they should attempt to separate as clearly as possible the objective and impartial professional advice that ought to come from an interdisciplinary group of consultants, from the policy objectives which should be left to elected representatives. It is implicit in the Paper that the Departmental engineers and subsequently the Roskill Research Team took it for granted that they were beyond suspicion of involvement in policy objectives or political prejudice. One accepts readily that they intended to be completely detached in this respect, but whether they really succeeded is debatable, and Parry Lewis has vigorously challenged it. $^{6}$

134. At the beginning of the shortlisting procedure a technical criterion is established which contains a high degree of political sociology and economic assumption, but which is easily represented as a simple application of a technical consideration. This is the elimination of sites causing an unacceptable noise burden and the orientation of runways so as to balance noise minimization against usability from the wind direction and air traffic control aspects. The reasons why this important and intricate part of the work was irreconcilable with subsequent analytical methods adopted by the Roskill Research Team are set out in reference 7 .

135. It would be unfair to reproach the Author or the Roskill Commission because the noise contours they agreed to adopt were shortly afterwards found to be highly misleading because of aircraft design improvements. For future reference engineers working on runway alignment problems, where noise is a consideration, should study the history of this affair in all its aspects, along with the lessons of the 
Public Inquiries for Edinburgh and Glasgow airports, in order to avoid becoming implicated in inadequately prepared propositions.

136. All the aspects of site selection listed in the Paper are clearly of importance and interest to engineers, but they are by no means of equal weight in their influence on site selection. Since the Roskill Commission had responded to the widespread demand for a cost/benefit attack on the problem, and since the relative importance of the various items in the cost/benefit balance sheet emerged at quite an early stage in the work, it might have become an objective of the Research Team to reach agreement with their more technically responsible potential critics, on the significance of various factors, and hence on the work that was justified in establishing and arguing the case. The insistence of the Commission on treating all witnesses as though they were objectors to the unknown conclusion of its work prevented this rational and timesaving procedure from being followed.

137. References $8-13$ are also important papers on this subject.

\section{Mr Dawson}

In reply to Mr Sharman, the Paper, already lengthy, dealt only with the engineering aspects. There was no substantial volume of outside engineering studies to which reference has not been made, although the degree of substance of much of the work must remain a matter of judgement.

139. There was no serious conflict between wind direction and air traffic control aspects and orientation of the airport to reduce noise nuisance at any of the sites with a reasonable chance of selection. The particular method used to assess noise nuisance would not have influenced orientation or the precise location at any of the shortlisted sites. The Wilson NNI contours were by no means 'highly misleading' and gave a reasonable indication of the degree of nuisance in the areas concerned. It is true that aircraft design improvements have reduced the noise problem. This has the effect of making the layouts adopted by the Research Team for Foulness more attractive in comparison with many external suggestions.

140. It was an objective of the Research Team to reach agreement, if possible, with potential critics before the public inquiry. In this, it was largely successful on the engineering aspects. The only significant engineering point of dispute was the relative cost of reclamation at Foulness, and earth moving at the inland sites. The views put forward on this subject were so extreme and its importance was so obvious that it was thought proper that the matter should be ventilated at the public inquiry.

141. In reply to Professor Francis, it is agreed that 'hydraulic' rather than 'hydrological' should have been used in $\S 54$.

142. In reply to Mr Clutterbuck, the same value was not, in effect, given to the low level polder type reclamation. The higher costs associated with the high level reclamation were adopted because of the flooding risk.

143. I should like to thank Mr Flaxman for explaining the apparent anomaly in regard to the sewage disposal costs at Foulness. In Table 3 Fowlmere and Nene should replace Furlmere and Nere and in Fig. 2 the 30 knot and 20 knot windspeeds have been interchanged. It is, of course, at the lower windspeeds that usability is greater.

144. In reply to Mr Howells, the implications of aircraft not moving under their own power between take-off and landing were not studied. The stand arrangements postulated were, however, based on 'push-back' by tractor and not 'free-manoeuvring' by aircraft.

\section{References}

6. Parry Lewis J. Mis-used techniques in planning: the forecasts of Roskill. British leisure passengers: the Commission's methods. Regional Studies, 1971, 5, No. 3, Sept. 
7. Sharman F. A. The Third London Airport as a project asssessment problem. Regional Studies, 1971, 5, No. 3, Sept.

8. SELF P. J. Nonsense on stilts. New Society, 1970, 2 July.

9. LichField N. Cost-benefit analysis in planning: a critique of the Roskill Commission. Regional Studies, 1971, 5, No. 3, Sept.

10. GriffrTHS E. Opening address-In Balancing Foulness. Regional Studies Association, London, 1972.

11. Peters W. D. Balancing Foulness (Maplin). In Balancing Foulness. Regional Studies Association, London, 1972.

12. SMITH A. and MUir Wood A. Balancing Foulness: trans-estuarial communications. In Balancing Foulness. Regional Studies Association, London, 1972.

13. Foster C. Some economic problems in implementing Foulness. In Balancing Foulness. Regional Studies Association, London, 1972. 